\title{
Efficiency of the Market for Racetrack Betting
}

\author{
Donald B. Hausch, William T. Ziemba and Mark Rubinstein ${ }^{\dagger}$ \\ received by Management Science on April 3, 1980 \\ (published under the same title in Management Science (December 1981))
}

[reprinted in Efficiency of Racetrack Betting Markets, edited by D. Hausch, V. Lo and W. Ziemba (Academic Press 1995)]

Many racetrack bettors have systems. Since the track is a market similar in many ways to the stock market one would expect that the basic strategies would be either fundamental or technical in nature. Fundamental strategies utilize past data available from racing forms, special sources, etc. to "handicap" races. The investor then wagers on one or more horses whose probability of winning exceeds that determined by the odds by an amount sufficient to overcome the track take. Technical systems require less information and only utilize current betting data. They attempt to find inefficiencies in the "market" and bet on such "overlays" when they have positive expected value. Previous studies and our data confirm that for win bets these inefficiencies, which exist for underbet favorites and overbet longshots, are not sufficiently great to result in positive profits.

This paper describes a technical system for place and show betting for which it appears to be possible to make substantial positive profits and thus to demonstrate market inefficiency in a weak form sense. Estimated theoretical probabilities of all possible finishes are compared with the actual amounts bet to determine profitable betting situations. Since the amount bet influences the odds and theory suggests that to maximize long run growth a logarithmic utility function is appropriate, the resulting model is a nonlinear program. Side calculations generally reduce the number of possible bets in any one race to three or less, hence the actual optimization is quite simple. The system was tested on data from Santa Anita and Exhibition Park using exact and approximate solutions (that make the system operational at the track given the limited time available for placing bets) and found to produce substantial positive profits. A model is developed to demonstrate that the profits are not due to chance but rather to proper identification of market inefficiencies.

\footnotetext{
${ }^{\dagger}$ The authors are at Northwestern University, University of British Columbia, and University of California, Berkeley, respectively. Without implicating them, we would like to thank Michael Alhadeff of Longacres Racetrack in Seattle, the American Totalizator Corporation and the staff of the Jockey Club at Exhibition Park in Vancouver for helping us obtain the data used in this study, and M.J. Brennan and E.U. Choo for helpful discussions. Thanks are also due to V.S. Bawa, J.R. Ritter, and two anonymous referees for helpful comments on an earlier draft of this paper. This paper is a condensation of Hausch, Ziemba and Rubinstein (1980).
} 


\section{The Racetrack Market}

For the most part, ${ }^{1}$ academic research on security markets has bypassed an interesting and accessible market - the racetrack for thoroughbred horses - with its highly standardized form of security - the tote ticket. The racetrack shares many of the characteristics of the archtypical securities market in listed common stocks. Moreover the racetrack gains further interest from its significant differences, and more importantly, because it is inherently a more elementary market context, lacking many of the dynamic features which complicate analysis of the stock market.

The "market" at the track in North America convenes for about 20 minutes, during which participants place bets on any number of the six to twelve horses in the following race. In a typical race, participants can bet on each horse, either to win, place or show. ${ }^{2}$ The horses that finish the race first, second or third are said to finish "in-the-money." All participants who have bet a horse to win, realize a positive return on that bet only if the horse is first, while a place bet realizes a positive return if the horse is first or second, and a show bet realizes a positive return if the horse is first, second or third. Regardless of the outcome, all bets have limited liability. Unlike most casino games such as roulette, but like the stock market, security prices (i.e. the "odds") are jointly determined by all participants and a rule governing transaction costs (i.e. the track "take"). To take the simplest case, for win, all bets across all horses to win are aggregated to form the win pool. If $W_{i}$ represents the total amount bet by all participants on horse $i$ to win, then $W=\sum_{i} W_{i}$ is the win pool and $W Q / W_{i}$ is the payoff per dollar bet on horse $i$ to win if and only if horse $i$ wins, where $1-Q$ is the percentage transaction costs. ${ }^{3}$ If horse $i$ does not win, the payoff per dollar bet is zero.

The track is "competitive" in the sense that every dollar bet on horse $i$ to win, regardless of the identification of the bettor, has the same payoff. The "state contingent" price of a dollar received if and only if horse $i$ wins is $\rho_{i}=\left(W_{i} / W Q\right)$ and the one plus riskless return is $1 / \sum_{i} \rho_{i}=Q$, a number less than one. The interest rate at the track is thus negative and solely determined by the level of transactions costs. Thus, apart from an exogeneously set riskless rate, the participants at the track jointly determine the security prices. For example, by betting more on one horse than another, the state-contingent price of the first horse increases relative to the second, or alternatively the payoff per dollar bet decreases on the first relative to the second.

The rules for division of the place and show pools are slightly more complex than the win pool. Let $P_{j}$ be the amount bet on horse $j$ to place and $P \equiv \sum_{j} P_{j}$ be the place pool. Similarly $S_{k}$ is the amount bet on horse $k$ to show and the show pool is $S \equiv \sum_{k} S_{k}$. The payoff per dollar bet on horse $j$ to place is

\footnotetext{
${ }^{1}$ For surveys, see Copeland and Weston (1979), Fama (1970, 1976), and Rubinstein (1975).

${ }^{2}$ Other bets such as the daily double (pick the winners in the first and second race), the quinella (pick the first two finishers regardless of order in a given race) and the exacta (pick the first two finishers in exact order in a given race) as well as various combinations are possible as well. Such bets are utilized by the public to construct low probability high payoff bets. For discussion of some of the implications of such bets see Rosett (1965).

${ }^{3}$ The actual transactions cost is more complicated and is described below.
} 


$$
\begin{aligned}
& 1+\left[P Q-P_{i}-P_{j}\right] /\left(2 P_{j}\right) \quad \text { if } \quad i \text { is first and } j \text { is second or } \\
& j \text { is first and } i \text { is second }
\end{aligned}
$$

otherwise.

Thus, if horses $i$ and $j$ are first and second, each bettor on $j$ (and also $i$ ) to place first receives the amount of his bet back. The remaining amount in the place pool, after the track take, is then split evenly between the place bettors on $i$ and $j$. The payoff to horse $j$ to place is independent of whether $j$ finishes first or second, but it is dependent on which horse finishes with it. A bettor on horse $j$ to place hopes that a longshot, not a favorite, will finish with it.

The payoff per dollar bet on show is analogous

$$
\begin{array}{ll}
1+\left[S Q-S_{i}-S_{j}-S_{k}\right] /\left(3 S_{k}\right) \text { if } \quad \begin{array}{l}
k \text { is first, second or third and finishes with } \\
i \text { and } j
\end{array} \\
0 & \text { otherwise. }
\end{array}
$$

In many ways the racetrack is like the stock market. A technical strategy based on discrepancies between the amounts bet on the same horses to win, place and show, is examined in this paper. Since a short position has a perfectly negative correlated outcome to the result of normal bet, a given horse can be "shorted" by buying tickets on all the other horses in a race.

The racetrack also differs from the stock market in important ways. In the stock market, an investor's profit depends not only on the initial price he pays for a security, but also on what some other investor is willing to pay him for it when he decides to sell. Thus his profit depends not only on how well the underlying firm does in terms of earnings over the time he holds it stock (i.e. supply uncertainty), but also on how other investors value that stock in the future (i.e. demand uncertainty). Given the initial price, both the nature and behavior of other market participants determine his profit. Thus current stock prices might depend not only on "fundamental" factors but also on market "psychology" - the tastes, beliefs, and endowments of other investors, etc. In contrast once all bets are placed at the track prior to a given race (i.e. initial security prices are given), the result of the race and the corresponding payoffs depend only on nature. There is no demand uncertainty at the track.

\section{Previous Work on Racetrack Efficiency}

A market is efficient if current security prices fully reflect all available relevant information. If this is the case, experts should not be able to achieve higher than average returns with regularity. A number of investigators have demonstrated that the New York Stock Exchange and other major security markets are efficient and so-called experts in fact achieve returns when adjusted for risk that are no higher than those that would be received from random investments (see Copeland and Weston (1979), Fama (1970, 1976) and Rubinstein (1975) for discussion, terminology, and relevant references). For an exception see Downes and Dyckman (1973). 
Snyder (1978) provided an investigation of the efficiency of the market for racetrack bets to win. The question Snyder poses is whether or not bets at different odds levels yield the same average return. The rate of return for odds group $i$ is

$$
R_{i}=\frac{N_{i}^{*}\left(O_{i}+1\right)-N_{i}}{N_{i}}
$$

where $N_{i}$ and $N_{i}^{*}$ are the number of horses, and the number who won, respectively, at odds $O_{i}=$ $\left(W Q / W_{i}-1\right)$. A weakly-efficient market in Snyder's sense would set $R_{i}=Q$ for all $i$ where $1-Q$ is the percentage track take. His results as well as those of Fabricant (1965), Griffith (1949, 1961), McClothlin (1956), Seligman (1975) and Weitzman (1965) suggest that there are "strong and stable biases, but these are not large enough to make it possible to earn a positive profit" (Snyder (1978), p. 1110). In particular, extreme favorites tend to be under bet and longshots overbet. The combined results of several studies comparing over 30,000 races are summarized in Table 1.

TABLE 1 (Snyder (1978))

Rates of Return on Bets to Win by Grouped Odds, Take Added Back

\begin{tabular}{lrrrrrrrr}
\hline & \multicolumn{8}{c}{ Midpoint of grouped odds } \\
\cline { 2 - 9 } Study & 0.75 & 1.25 & 2.5 & 5.0 & 7.5 & 10.0 & 15.0 & 33.0 \\
\hline Fabricant & $11.1^{\mathrm{a}}$ & $9.0^{\mathrm{a}}$ & $4.6^{\mathrm{a}}$ & -1.4 & -3.3 & -3.7 & -8.1 & $-39.5^{\mathrm{a}}$ \\
Griffith & 8.0 & 4.9 & 3.1 & -3.1 & $-34.6^{\mathrm{a}}$ & $-34.1^{\mathrm{a}}$ & -10.5 & $-65.5^{\mathrm{a}}$ \\
McGlothlin & $8.0 \mathrm{~b}$ & $8.0^{\mathrm{a}}$ & $8.0^{\mathrm{a}}$ & -0.8 & -4.6 & $-7.0^{\mathrm{b}}$ & -9.7 & -11.0 \\
Seligman & 14.0 & 4.0 & -1.0 & 1.0 & -2.0 & -4.0 & -7.8 & -24.2 \\
Snyder & 5.5 & 5.5 & 4.0 & -1.2 & 3.4 & 2.9 & 2.4 & -15.8 \\
Weitzman & $9.0^{\mathrm{a}}$ & 3.2 & $6.8^{\mathrm{a}}$ & -1.3 & -4.2 & -5.1 & $-8.2^{\mathrm{b}}$ & $-18.0^{\mathrm{a}}$ \\
\hline Combined & $9.1^{\mathrm{a}}$ & $6.4^{\mathrm{a}}$ & $6.1^{\mathrm{a}}$ & -1.2 & $-5.2^{\mathrm{a}}$ & $-5.2^{\mathrm{a}}$ & $-10.2^{\mathrm{a}}$ & $-23.7^{\mathrm{a}}$ \\
\hline
\end{tabular}

${ }^{a}$ Significantly different from zero at $1 \%$ level or better.

${ }^{\mathrm{b}}$ Significantly different from zero at $5 \%$ level or better.

Since the track take averages about $18 \%$, the net rate of return for any strategy that consistently bets within a single odds category is $-9 \%$ or less. For horses with odds averaging 33 the net rate of return is about $-42 \%$.

Conventional financial theory does not explain these biases because it is usual to assume that as nondiversifiable risk (e.g. variance) rises expected return rises as well. In the win pool, expected return declines as risk increases. An explanation consistent with the expected utility hypothesis is that investors (as a composite) are risk lovers and behave as if the betting opportunities are limited to a single race. Weitzman (1965) and Ali (1977) have estimated such utility functions. Ali's estimated utility function over wealth $w$ is the convex function 


$$
u(x)=1.191 w^{1.1784} \quad\left(R^{2}=.9981\right)
$$

which has increasing absolute risk aversion. Thus by the Arrow-Pratt $(1964,1965)$ theory investors will take more risk as their wealth declines. This explains the common phenomenon that bettors, when losing, tend to bet more and more on longer odds horses in a desperate attempt to recoup earlier losses. Moreover, since $u$ is nearly linear for large $w$, investors are nearly risk neutral at such wealth levels.

A second explanation is that gamblers simply prefer low probability high prize combinations (i.e. longshots) to high probability low prize combinations. Besides the possible gains involved, gamblers have egos associated with analyzing racing forms and pitting one's predictions against others. Luck and entertainment as well are largely absent in betting favorites. The thrill is to successfully detect a moderate or long odds winner and thus confirm one's ability to outperform the other bettors. Such a scenario is consistent with the data and leads to the biases. Rossett (1965) provides an analysis of ways to construct low probability-high prize bets through parlays and other combinations that can be used to avoid the longshot tail bias problem and to take advantage of the favorite bias. In an effort to capitalize on this market, many tracks feature such bets in the form of the daily double, the exacta and the quinella. However, none of these schemes appear to yield bets with positive net returns. ${ }^{4}$

Other studies of racetrack efficiency have been conducted by Ali (1979), Figlewski (1979) and Snyder (1978). Ali shows that the win market is efficient in the sense that independently derived bets with identical probabilities of winning do in fact have the same odds in a statistical sense. His analysis utilizes daily double bets and the corresponding parlays, i.e. bet the proceeds if the chosen horse wins the first race on the chosen horse in the second race, for 1089 races. Figlewski, using a multinomial logit probability model to measure the information content of the forecasts of professional handicappers and data from 189 races at Belmont in 1977, found that these forecasts do contain considerable information but the track odds generated by bettors discount almost all of it. Snyder provided strong form efficiency tests of the form: are there persons with special information that would allow them to outperform the general public? He found using data on 846 races at Arlington Park in Chicago that forecasts from three leading newspapers, the daily racing form and the official track handicapper did not lead to bets that outperformed the general public.

\section{Proposed Test}

The studies described in Section 2 examine racetrack efficiency with respect to the win pool only. In this paper our concern is with the efficiency of the place and show pools relative to the win pool and with the development of procedures to best capitalize on potential inefficiencies between these three "markets." We utilize the following definition of weak-form efficiency: the market is weakly-efficient if no individual can earn positive profits using trading rules based on historical price information. In Baumol's (1965, p. 46) words ... "all opportunities for profit by systematic betting are eliminated." Our analysis utilizes the following two data sets: 1) Data Set

\footnotetext{
${ }^{4}$ For an entertaining account of an "expert" who was able to achieve positive net returns over a full racing season, see Beyer (1978). See also Vergin (1977).
} 
1: all dollar bets to win, place and show for the 627 races over 75 days involving 5,895 horses running in the 1973/74 winter season at Santa Anita Racetrack in Arcadia, California, collected by Mark Rubinstein; and 2) Data Set 2: all dollar bets to win, place and show for the 1,065 races over 110 days involving 9,037 horses running in the 1978 summer season at Exhibition Park, Vancouver, British Columbia, collected by Donald Hausch and William Ziemba.

In the analysis of the efficiency of the win pool, one may compare the actual frequency of winning with the theoretical probability of winning as reflected through the odds. Similar analyses are possible for the place and show pools once an estimate of the theoretical probabilities of placing and showing for all horses is available. There is no unique way to obtain these estimates. However, very reasonable estimates obtain from the natural generalization of the following simple procedure. Suppose three horses have probabilities to win of $0.5,0.3$, and 0.2 , respectively. Now if horse 2 wins, a Bayesian would naturally expect that the probabilities that horses 1 and 3 place (i.e. win second place) are $0.5 / 0.7$ and $0.2 / 0.7$, respectively. In general, if $q_{i}(i=1, \ldots, n)$ is the probability horse $i$ wins, then the probability that $i$ is first and $j$ is second is

$$
\left(q_{i} q_{j}\right) /\left(1-q_{i}\right)
$$

and the probability that $i$ is first, $j$ is second and $k$ is third is

$$
q_{i} q_{j} q_{k} /\left(1-q_{i}\right)\left(1-q_{i}-q_{j}\right)
$$

Harville (1973) gives an analysis of these formulas. Despite their apparent reasonableness they suffer from at least two flaws:

1) no account is made of the possibility of the "Silky Sullivan" problem; that is, some horses generally either win or finish out-of-the-money-for example, see footnote 5 in Hausch, Ziemba and Rubinstein (1980); for these horses the formulas greatly over-estimate the true probability of finishing second or third; and

2) the formulas are not derivable from first principles involving individual horses running times; even independence of these random variables $T_{1}, \ldots, T_{n}$ is neither necessary nor sufficient to imply the formulas.

In addition to assuming (1) and (2), we assume that

$$
q_{i}=W_{i} / \sum_{i=1}^{n} W_{i}
$$

That is, the win pool is efficient. The discussion above, of course, indicates that this assumption is suspect in the tails, and this is discussed below. Table 2a-c compares the actual versus theoretical probability of winning, placing and showing for data set 2 . Similar tables for data set 1 appear in King (1978); see also Harville (1973). The usual tail biases appear in Table 2a (although they are not significant at the 5\% confidence level). One has reverse tail biases in the 
finishing second and third probabilities, see Tables $2 \mathrm{~b}$ and $2 \mathrm{c}$ in Hausch, Ziemba and Rubinstein (1980). This occurs because if the probability to win is overestimated (underestimated) and probabilities sum to one, it is likely that the probabilities of finishing second and third would be underestimated (overestimated). Tables $2 \mathrm{~b}$ and $2 \mathrm{c}$, indicate how these biases tend to cancel when they are aggregated to form the theoretical probabilities and frequencies of placing and showing.

TABLE 2

Actual vs. Theoretical Probability of Winning, Placing and Showing: Exhibition Park 1978

\begin{tabular}{|c|c|c|c|c|c|c|}
\hline \multirow[t]{12}{*}{ (a) } & \multicolumn{2}{|c|}{$\begin{array}{l}\text { Theoretical } \\
\text { Probability of } \\
\text { Winning }\end{array}$} & $\begin{array}{l}\text { Number } \\
\text { of } \\
\text { Horses }\end{array}$ & $\begin{array}{c}\text { Average } \\
\text { Theoretical } \\
\text { Probability }\end{array}$ & $\begin{array}{l}\text { Actual } \\
\text { Frequency } \\
\text { of Winning }\end{array}$ & $\begin{array}{l}\text { Estimated } \\
\text { Standard } \\
\text { Error }\end{array}$ \\
\hline & 0.000 & -0.025 & 540 & 0.019 & 0.016 & 0.005 \\
\hline & 0.026 & -0.050 & 1,498 & 0.037 & 0.036 & 0.005 \\
\hline & 0.051 & -0.100 & 2,658 & 0.073 & 0.079 & 0.005 \\
\hline & 0.101 & -0.150 & 1,772 & 0.123 & 0.126 & 0.008 \\
\hline & 0.151 & -0.200 & 1,199 & 0.172 & 0.156 & 0.010 \\
\hline & 0.201 & -0.250 & 646 & 0.223 & 0.227 & 0.016 \\
\hline & 0.251 & - 0.300 & 341 & 0.272 & 0.263 & 0.024 \\
\hline & 0.301 & -0.350 & 199 & 0.323 & 0.306 & 0.033 \\
\hline & 0.351 & -0.400 & 101 & 0.373 & 0.415 & 0.049 \\
\hline & \multirow{2}{*}{\multicolumn{2}{|c|}{$0.401+$}} & 83 & 0.450 & 0.469 & 0.055 \\
\hline & & & 037 & & & \\
\hline
\end{tabular}

\footnotetext{
${ }^{5}$ Since it is the accuracy of these probabilities rather than the $q_{i}$ 's that is of crucial importance in the calculations and model below, this canceling provides some justification for omitting the tail biases in (3). In practice, bets are only made on horses with expected returns considerably above 1, e.g., 1.16 at Santa Anita. Modification of the $q_{i}$ to include these biases might change the 1.16 to 1.14 , for example. See also the discussion below and in Sections 4 and 5.
} 


\begin{tabular}{crrrrr}
\hline (b) $\begin{array}{c}\text { Theoretical } \\
\text { Probability of } \\
\text { Placing }\end{array}$ & $\begin{array}{c}\text { Number } \\
\text { of } \\
\text { Horses }\end{array}$ & $\begin{array}{c}\text { Average } \\
\text { Theoretical } \\
\text { Probability }\end{array}$ & $\begin{array}{c}\text { Actual } \\
\text { Frequency } \\
\text { of Placing }\end{array}$ & $\begin{array}{c}\text { Estimated } \\
\text { Standard } \\
\text { Error }\end{array}$ \\
\hline $0.000-0.025$ & 21 & 0.022 & $0.000^{*}$ & 0.000 \\
$0.026-0.050$ & 391 & 0.040 & 0.030 & 0.009 \\
$0.051-0.100$ & 1,394 & 0.075 & 0.080 & 0.007 \\
$0.101-0.150$ & 1,335 & 0.124 & $0.152^{*}$ & 0.010 \\
$0.151-0.200$ & 1,295 & 0.174 & 0.174 & 0.011 \\
$0.201-0.250$ & 1,057 & 0.223 & 0.243 & 0.013 \\
$0.251-0.300$ & 871 & 0.274 & 0.304 & 0.016 \\
$0.301-0.350$ & 772 & 0.323 & 0.314 & 0.017 \\
$0.351-0.400$ & 580 & 0.373 & $0.313 *$ & 0.019 \\
$0.401-0.450$ & 420 & 0.424 & 0.395 & 0.024 \\
$0.451-0.500$ & 321 & 0.472 & 0.457 & 0.028 \\
$0.501-0.550$ & 202 & 0.523 & $0.415^{*}$ & 0.035 \\
$0.551-0.600$ & 149 & 0.573 & $0.483 *$ & 0.041 \\
$0.601-0.650$ & 114 & 0.623 & 0.570 & 0.046 \\
$0.651-0.700$ & 51 & 0.672 & 0.627 & 0.068 \\
$0.701-0.750$ & 41 & 0.721 & 0.731 & 0.069 \\
$0.751+$ & & 23 & 0.792 & 0.782 & 0.086 \\
\cline { 6 - 7 } & 9,037 & & & \\
\hline
\end{tabular}




\begin{tabular}{|c|c|c|c|c|c|c|}
\hline \multirow[t]{21}{*}{ (c) } & \multicolumn{2}{|c|}{$\begin{array}{c}\text { Theoretical } \\
\text { Probability of } \\
\text { Showing } \\
\end{array}$} & \multirow{2}{*}{$\begin{array}{r}\begin{array}{c}\text { Number } \\
\text { of } \\
\text { Horses }\end{array} \\
0\end{array}$} & \multirow{2}{*}{$\begin{array}{c}\text { Average } \\
\text { Theoretical } \\
\text { Probability } \\
-\end{array}$} & \multirow{2}{*}{$\begin{array}{c}\begin{array}{c}\text { Actual } \\
\text { Frequency } \\
\text { of Showing }\end{array} \\
-\end{array}$} & \multirow{2}{*}{$\begin{array}{c}\text { Estimated } \\
\text { Standard } \\
\text { Error } \\
-\end{array}$} \\
\hline & 0.000 & -0.025 & & & & \\
\hline & 0.026 & -0.050 & 55 & 0.043 & 0.036 & 0.025 \\
\hline & 0.051 & -0.100 & 592 & 0.078 & 0.081 & 0.011 \\
\hline & 0.101 & -0.150 & 895 & 0.125 & $0.165^{*}$ & 0.012 \\
\hline & 0.151 & -0.200 & 909 & 0.175 & 0.195 & 0.013 \\
\hline & 0.201 & -0.250 & 799 & 0.224 & $0.292 *$ & 0.016 \\
\hline & 0.251 & -0.300 & 885 & 0.275 & 0.289 & 0.015 \\
\hline & 0.301 & -0.350 & 794 & 0.324 & 0.346 & 0.017 \\
\hline & 0.351 & -0.400 & 703 & 0.374 & 0.398 & 0.018 \\
\hline & 0.401 & -0.450 & 655 & 0.425 & 0.433 & 0.019 \\
\hline & 0.451 & -0.500 & 617 & 0.475 & 0.452 & 0.020 \\
\hline & 0.501 & -0.550 & 542 & 0.524 & $0.477 *$ & 0.021 \\
\hline & 0.551 & -0.600 & 396 & 0.573 & $0.477 *$ & 0.025 \\
\hline & 0.601 & -0.650 & 375 & 0.624 & 0.599 & 0.025 \\
\hline & 0.651 & -0.700 & 264 & 0.672 & $0.609 *$ & 0.030 \\
\hline & 0.701 & -0.750 & 206 & 0.722 & $0.582 *$ & 0.034 \\
\hline & 0.751 & -0.800 & 154 & 0.773 & $0.655^{*}$ & 0.038 \\
\hline & 0.801 & -0.850 & 113 & 0.821 & 0.752 & 0.041 \\
\hline & 0.851 & -0.900 & 53 & 0.873 & 0.830 & 0.052 \\
\hline & \multirow{2}{*}{\multicolumn{2}{|c|}{$0.901+$}} & 30 & 0.925 & 0.833 & 0.068 \\
\hline & & & 9,037 & & & \\
\hline
\end{tabular}

${ }^{a}$ Categories for which the theoretical probability and the actual frequency are different at the $5 \%$ significance level are denoted by *'s. The estimated standard error is $\left(s^{2} / N\right)^{1 / 2}$ where the actual frequency sample variance $s^{2}=N\left(E\left(X^{2}\right)\right.$ $\left.-\mathrm{E}(\mathrm{X})^{2}\right) /(N-1)$. Since the $X_{i}$ are either 0 or $1, E\left(X^{2}\right)=E X$ and $s^{2}=N\left(E X-(E X)^{2}\right) /(N-1)$.

Formulas (1)-(3) can be used to develop procedures that yield net rates of return for place and show betting that are higher than expected (i.e. $-18 \%$ ) and indeed make positive profits. As a first step towards development of a "system," we present the results on the two data sets of $\$ 1$ bets when the theoretical expected return is $\alpha$ for varying $\alpha$. The expected return from a $\$ 1$ bet to place on horse $l$ is ${ }^{6,7}$

$$
E X_{l}^{p} \equiv \sum_{\substack{j=l \\ j \neq l}}^{n}\left(\frac{q_{l} q_{j}}{1-q_{l}}\right)\left[1+\frac{1}{20} I N T\left\{\left(\frac{Q(P+1)-\left(1+P_{l}+P_{j}\right)}{2}\right)\left(\frac{1}{1+P_{l}}\right) \times 20\right\}\right]
$$

\footnotetext{
${ }^{6}$ The expressions (4) and (5) give the marginal expected return for an additional $\$ 1$ bet to place or show on horse $l$. To obtain the average expected rates of return one simply replaces $\left(1+p_{l}\right)$ and $\left(1+s_{l}\right)$ in these expressions by $p_{l}$ and $s_{l}$, respectively. From a practical point of view, with usual track data, these quantities are virtually identical.

${ }^{7}$ A further complication, not reflected in (4) and (5) below, is that a $\$ 2$ winning bet must return at least $\$ 2.10$. Hence in these "minus pools" involving an extreme favorite, the track's take is less than $1-Q$.
} 


$$
+\sum_{\substack{i=1 \\ i \neq l}}^{n}\left(\frac{q_{i} q_{l}}{1-q_{i}}\right)\left[1+\frac{1}{20} \operatorname{INT}\left\{\left(\frac{Q(P+1)-\left(1+P_{i}+P_{l}\right.}{2}\right)\left(\frac{1}{1+P_{l}}\right) \times 20\right\}\right]
$$

where $Q$ is 1 minus the track take, $P \equiv \Sigma P_{i}$ is the place pool, $P_{i}$ is bet on horse $i$ to place and INT $(Y)$ means the largest integer not exceeding $Y$. In (4) the quantities $P$ and $P_{i}$ are the amounts bet before an additional $\$ 1$ is bet; similarly with $S$ and $S_{i}$ in (5), below. The expressions involving INT take into account the fact that $\$ 2$ bets return payoffs rounded down to the nearest $\$ 0.10$. The two expressions represent the expected payoffs if $l$ is first or second, respectively. Similarly, the expected payoff from a $\$ 1$ bet to show on horse $l$ is

$$
\begin{aligned}
E X_{l}^{s} \equiv & \sum_{\substack{j=1 \\
j \neq l}}^{n} \sum_{\substack{k=1 \\
k \neq l j}}^{n} \frac{q_{l} q_{j} q_{k}}{\left(1-q_{l}\right)\left(1-q_{l}-q_{j}\right)} \times\left[1+\frac{1}{20} \operatorname{INT}\left\{\left(\frac{Q(S+1)-\left(1+S_{l}+S_{j}+S_{k}\right)}{3}\right)\left(\frac{1}{1+S_{l}}\right) \times 20\right\}\right] \\
& +\sum_{\substack{i=1 \\
i \neq l}}^{n} \sum_{\substack{k=1 \\
k \neq i, l}}^{n} \frac{q_{i} q_{l} q_{k}}{\left(1-q_{i}\right)\left(1-q_{i}-q_{l}\right)} \times\left[1+\frac{1}{20} \operatorname{INT}\left\{\left(\frac{Q(S+1)=\left(1+S_{i}+S_{l}+S_{k}\right.}{3}\right)\left(\frac{1}{1+S_{l}}\right) \times 20\right\}\right] \\
+ & \sum_{\substack{i=1 \\
i \neq l}}^{n} \sum_{\substack{j=1 \\
j \neq l, i}}^{n} \frac{q_{i} q_{j} q_{l}}{\left(1-q_{i}\right)\left(1-q_{i}-q_{l}\right)} \times\left[1+\frac{1}{20} \operatorname{INT}\left\{\left(\frac{Q(S+1)-\left(1+S_{i}+S_{j}+S_{l}\right.}{3}\right)\left(\frac{1}{1+S_{l}}\right) \times 20\right\}\right]
\end{aligned}
$$

where $S \equiv \Sigma S_{i}$ is the show pool, $S_{i}$ is bet on horse $i$ to show and the three expressions represent the expected payoffs if $l$ is first, second and third, respectively.

Naturally one would expect that positive profits would not be obtained, given the inherent inaccuracies in assumptions (1)-(3), unless the theoretical expected return $\alpha$ were significantly greater than 1. However, we might hope that the actual rate of return would at least increase with $\alpha$ and be somewhat near $\alpha$. Table 3 indicates this is true for both data sets. The perverse behavior for high $\alpha$ in the place pool is presumably a small sample phenomenon. Additional calculations along these lines appear in Harville (1973). 
TABLE 3

Results of Betting \$1 to Place or Show on Horses with a Theoretical Expected Return of at Least $\alpha$

Exhibition Park

\begin{tabular}{|c|c|c|c|c|c|c|}
\hline \multirow[b]{2}{*}{$\alpha$} & \multicolumn{3}{|c|}{ Place } & \multicolumn{3}{|c|}{ Show } \\
\hline & $\begin{array}{c}\text { Number of } \\
\text { Bets }\end{array}$ & $\begin{array}{l}\text { Total Net } \\
\text { Profit }(\$)\end{array}$ & $\begin{array}{l}\text { Net Rate of } \\
\text { Return (\%) }\end{array}$ & $\begin{array}{c}\text { Number of } \\
\text { Bets }\end{array}$ & $\begin{array}{l}\text { Total Net } \\
\text { Profit }(\$)\end{array}$ & $\begin{array}{l}\text { Net Rate of } \\
\text { Return }(\%)\end{array}$ \\
\hline 1.04 & 225 & 5.10 & 2.3 & 612 & 33.20 & 5.4 \\
\hline 1.08 & 126 & -10.10 & -8.0 & 386 & 53.50 & 13.9 \\
\hline 1.12 & 69 & 11.10 & 16.1 & 223 & 40.80 & 18.3 \\
\hline 1.16 & 40 & 5.10 & 12.8 & 143 & 26.30 & 18.4 \\
\hline 1.20 & 18 & 5.30 & 29.4 & 95 & 21.70 & 22.8 \\
\hline 1.25 & 11 & -2.70 & -24.5 & 44 & 11.20 & 25.5 \\
\hline 1.30 & 3 & -3 & -100.0 & 27 & 10.80 & 40.0 \\
\hline 1.50 & 0 & 0 & - & 3 & 6 & 200.0 \\
\hline \multicolumn{7}{|c|}{ Santa Anita } \\
\hline & \multicolumn{3}{|c|}{ Place } & \multicolumn{3}{|c|}{ Show } \\
\hline$\alpha$ & $\begin{array}{c}\text { Number of } \\
\text { Bets }\end{array}$ & $\begin{array}{l}\text { Total Net } \\
\text { Profit (\$) }\end{array}$ & $\begin{array}{l}\text { Net Rate of } \\
\text { Return }(\%)\end{array}$ & $\begin{array}{c}\text { Number of } \\
\text { Bets }\end{array}$ & $\begin{array}{l}\text { Total Net } \\
\text { Profit }(\$)\end{array}$ & $\begin{array}{l}\text { Net Rate of } \\
\text { Return }(\%)\end{array}$ \\
\hline 1.04 & 103 & 12.30 & 11.9 & 307 & -18.00 & -5.9 \\
\hline 1.08 & 52 & 12.80 & 24.6 & 162 & 6.90 & 4.3 \\
\hline 1.12 & 22 & 9.20 & 41.8 & 89 & 3.00 & 3.4 \\
\hline 1.16 & 7 & 2.30 & 32.9 & 46 & 12.40 & 27.0 \\
\hline 1.20 & 3 & -1.30 & -43.3 & 27 & 6.20 & 23.0 \\
\hline 1.25 & 0 & 0 & - & 9 & 6.00 & 66.7 \\
\hline 1.30 & 0 & 0 & - & 5 & 5.10 & 102.0 \\
\hline 1.50 & 0 & 0 & - & 0 & 0 & - \\
\hline
\end{tabular}

\section{A Betting Model}

The results in Table 3 give a strong indication that there are significant inefficiencies in the place and show pools and that it is possible not only to achieve above average returns but to make substantial profits. In this section we develop a model indicating not only which horses should be bet but also how much should be bet, taking into account investor preferences and wealth levels and the effect of bet size on the odds.

We consider an investor having initial wealth $w_{0}$ contemplating a series of bets. It is natural to suppose that the investor would wish to maximize the long run rate of asset growth and thus employ the so-called Bernoulli capital growth model; see Ziemba and Vickson (1975) for references and discussion of various assumptions and results. We use the following result: if in each time period $t=1,2, \ldots$ there are $I$ investment opportunities with returns per unit invested denoted by the random variables $x_{t 1}, \ldots, x_{t I}$, where $x_{t i}$ have finitely many distinct values and for 
distinct $t$ the families are independent, then maximizing $E\left[\log \Sigma \lambda_{t i} x_{t i}\right]$, subject to $\Sigma \lambda_{t i} \leq w_{t}, \lambda_{t i} \geq 0$ maximizes the asymptotic rate of asset growth. The assumptions are quite reasonable in a horseracing context because there are a finite number of return possibilities and the race by race returns are likely to be nearly independent since different horses will be running (although the jockeys and trainers may not be).

The second key feature of the model is that it considers an investor's ability to influence the odds by the size of his bets. ${ }^{8}$ This yields the following model to calculate the optimal amounts to bet for place and show.

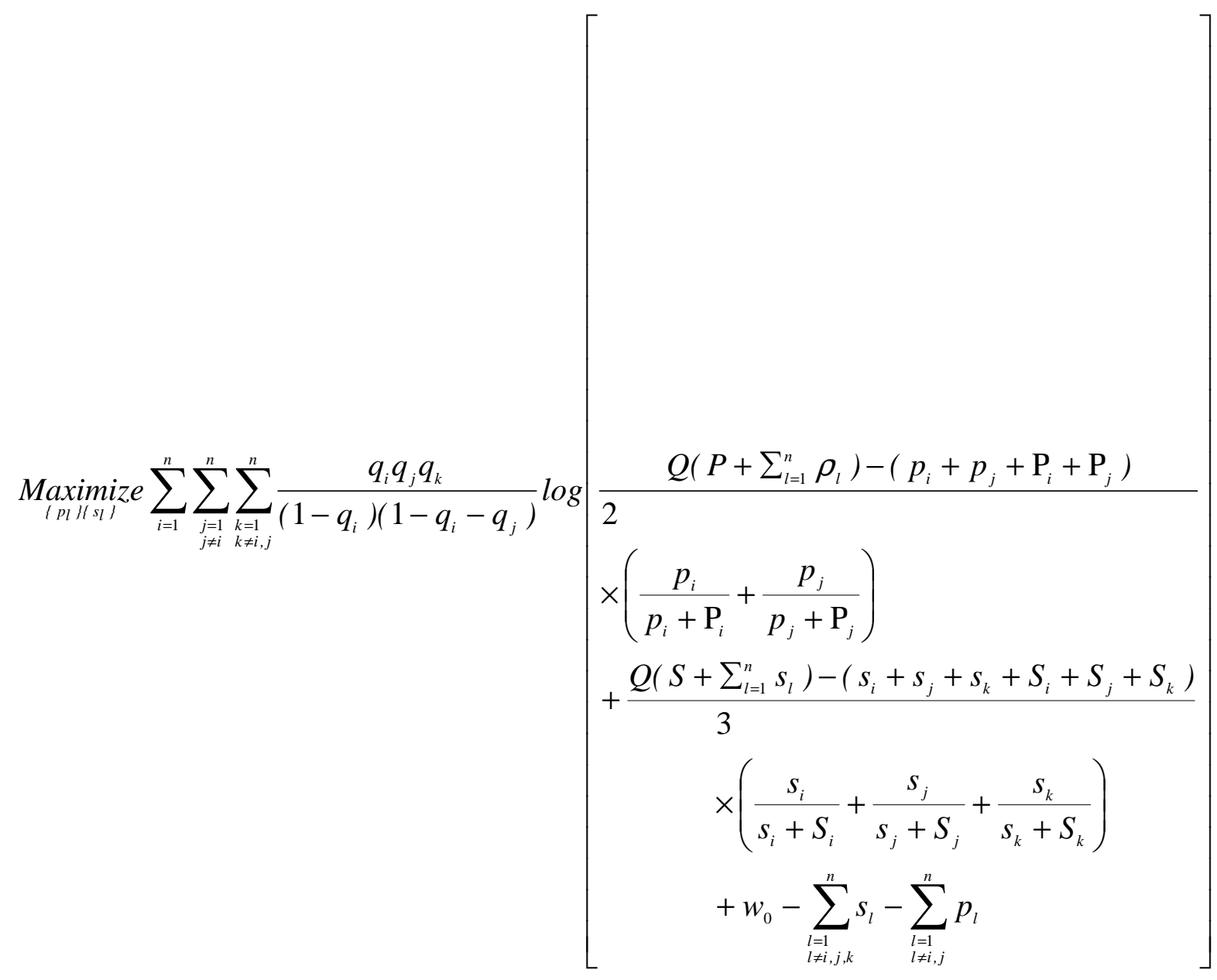

(6)

$$
\text { subject to } \sum_{l=1}^{n}\left(p_{l}+s_{l}\right) \leq w_{0}, \quad p_{l} \geq 0, s_{l} \geq 0, l=1, \ldots, n \text {, }
$$

\footnotetext{
${ }^{8}$ The first model to include this feature seems to be Isaacs (1953). Only win bets are considered with linear utility, and he is able to determine the exact solution in closed form. His model may be useful in situations where the perfect market assumption (3) is violated or where special expertise leads one to believe their estimates of the $q_{i}$ are better than those of the other bettors.
} 
where $Q=1-$ the track take, $W_{i}, P_{j}$ and $S_{k}$ are the total dollar amounts bet to win, place and show on the indicated horses by the crowd, respectively, $W \equiv \sum W_{i}, P \equiv \sum P_{j}$ and $S \equiv \sum S_{k}$ are the win, place and show pools, respectively, $q_{i} \equiv W_{i} / W$ is the theoretical probability that horse $i$ wins, $w_{0}$ is initial wealth and $p_{l}$ and $s_{l}$ are the investor's bets to place and show on horse $l$, respectively.

The formulation (6) maximizes the expected logarithm of final wealth considering the probabilities and payoffs from all possible horserace finishes. It is exact except for the minor adjustment made that the rounding down to the nearest $\$ 0.10$ for a two-dollar bet, see (4) and (5), is omitted. ${ }^{9}$ For the values of $\alpha \geq 1.16$ it was observed that in a given race at most three $\rho_{l}$ and three $s_{l}$ were nonzero. When (6) is then simplified, it can be solved in less than 1 second of CPU time. ${ }^{10}$ A discussion of the generalized concavity properties of (6) will appear in a forthcoming paper by Kallberg and Ziemba.

The results are illustrated by function 1 in Figures 1 and 2 for the two data sets using an initial wealth of $\$ 10,000$. In both cases the bet produced from (6) lead to well above average returns and to positive profits. ${ }^{11}$ These results may be contrasted with random betting; function 2 in Figures 1 and 2. Intuition suggests that Santa Anita with its larger betting pools would have more accurate estimates of the $q_{i}$ than would be obtained at Exhibition Park. Hence positive profits would result from lower values of $\alpha$. The results bear this out, and only horses with $\alpha \geq$ 1.20 for Exhibition Park were considered for possible bets. Generally speaking the bets are usually favorites and almost always on those horses with maximum $\left(W_{i} / W\right) /\left(P_{i} / P\right)$ and $\left(W_{i} / W\right) /\left(S_{i} / S\right)$ ratios. These ratios of the theoretical probability of winning to the track take unadjusted odds to place or show form a type of cost-benefit ratio that provides a first approximation to $\alpha$. This is discussed further in Section 5, below. Most of the bets are to show and one tends to bet only about once per day. The numbers of bets and their size distribution are presented in Table 4. As expected, the influence on the odds made by our investor's bets is much greater at Exhibition Park, hence the bets there tend to be much smaller than at Santa Anita. However, even there about $10 \%$ of the bets exceed $\$ 1,000$.

\footnotetext{
${ }^{9}$ It is possible to include this feature in (6) but it greatly complicates the solution procedure (e.g. differentiability is lost) with little added gain in accuracy.

10 All calculations were made on UBC's AMDAHL 470V6 Model II computer using a code for the generalized reduced gradient algorithm.

11 The procedure was to calculate the optimal bets to place and show in each race using (6) with the present wealth level. The results of the race and the actual payoffs that reflect the track's take and breakage are known. The payoff for our investor's bets were calculated using all the bets of the crowd plus the bets of our investor taking into account the track's take and breakage, i.e. the payoffs are thus those that would have occurred had our investor actually made his bets. The wealth level was then adjusted to reflect the race's gain or loss, and the procedure continued for all races.
} 
18,000

16,000

14,000

12,000

$W_{0}=10,000$

8,000

6,000

4,000

2,000

0

$\begin{array}{lllllllll}0 & 10 & 20 & 30 & 40 & 50 & 60 & 70 & 80\end{array}$

DAYS

1 Results from expected log betting to place and show when expected returns are 1.16 or better with initial wealth $\$ 10,000$.

2 Approximate wealth level history for random horse betting. Total dollars bet is as in system 1 (\$116,074). Track payback is $82.5 \%$; therefore final wealth level is $\$ 10,000-0.175(\$ 116,074)=-\$ 10,313$. (Note: breakage is not taken into consideration.)

3 Results from using the Exhibition Park approximate regression scheme (with initial wealth \$2,500) at Santa Anita.

FIGURE 1. Wealth Level Histories for Alternative Betting Schemes; Santa Anita: 1973/74 Season.

The log formulation has absolute risk aversion $1 / w$, which for wealth around $\$ 10,000$ is virtually zero. Zero absolute risk aversion is, of course, achieved by linear utility. One then will bet on the horse (or horses) with the highest $\alpha$, etc., continuing until there are no favorable bets or the betting wealth has been fully utilized. The results of such linear utility betting with $w_{0}=\$ 10,000$ are: at Exhibition Park with $\alpha \geq 1.20$, final wealth is $\$ 14,818$; at Santa Anita with $\alpha \geq 1.16$, final wealth is $\$ 10,910$. Such a strategy is a very risky one and leads to some very large bets. The log function has the distinct advantage that it implies negative infinite utility at zero wealth; hence bets having any significant probability of yielding final wealth near zero are avoided. 


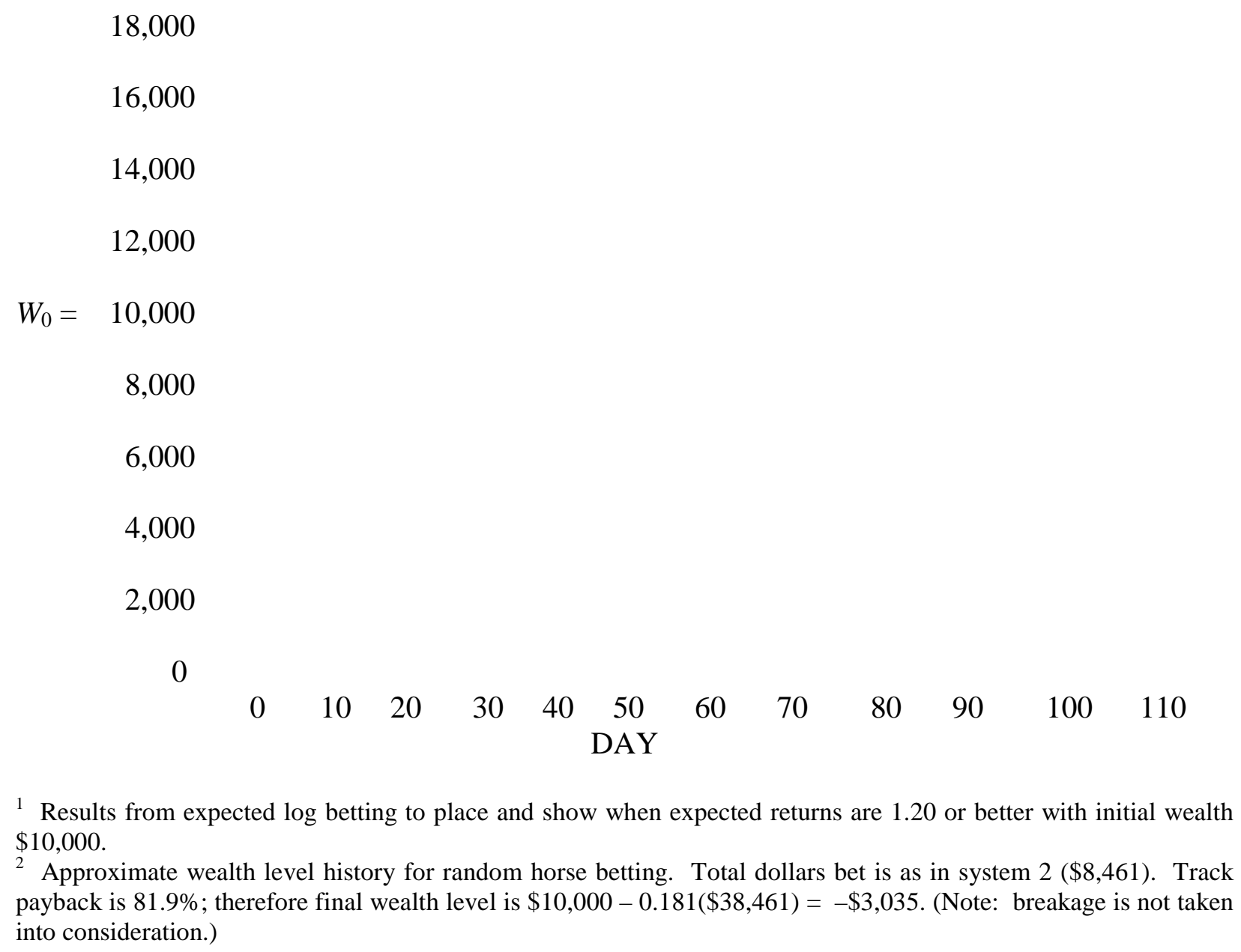

FIGURE 2. Wealth Level Histories for Alternative Betting Schemes; Exhibition Park: 1978 Season. 
TABLE 4

Size Distribution of Bets, $w_{0}=\$ 10,000$, Log Utility

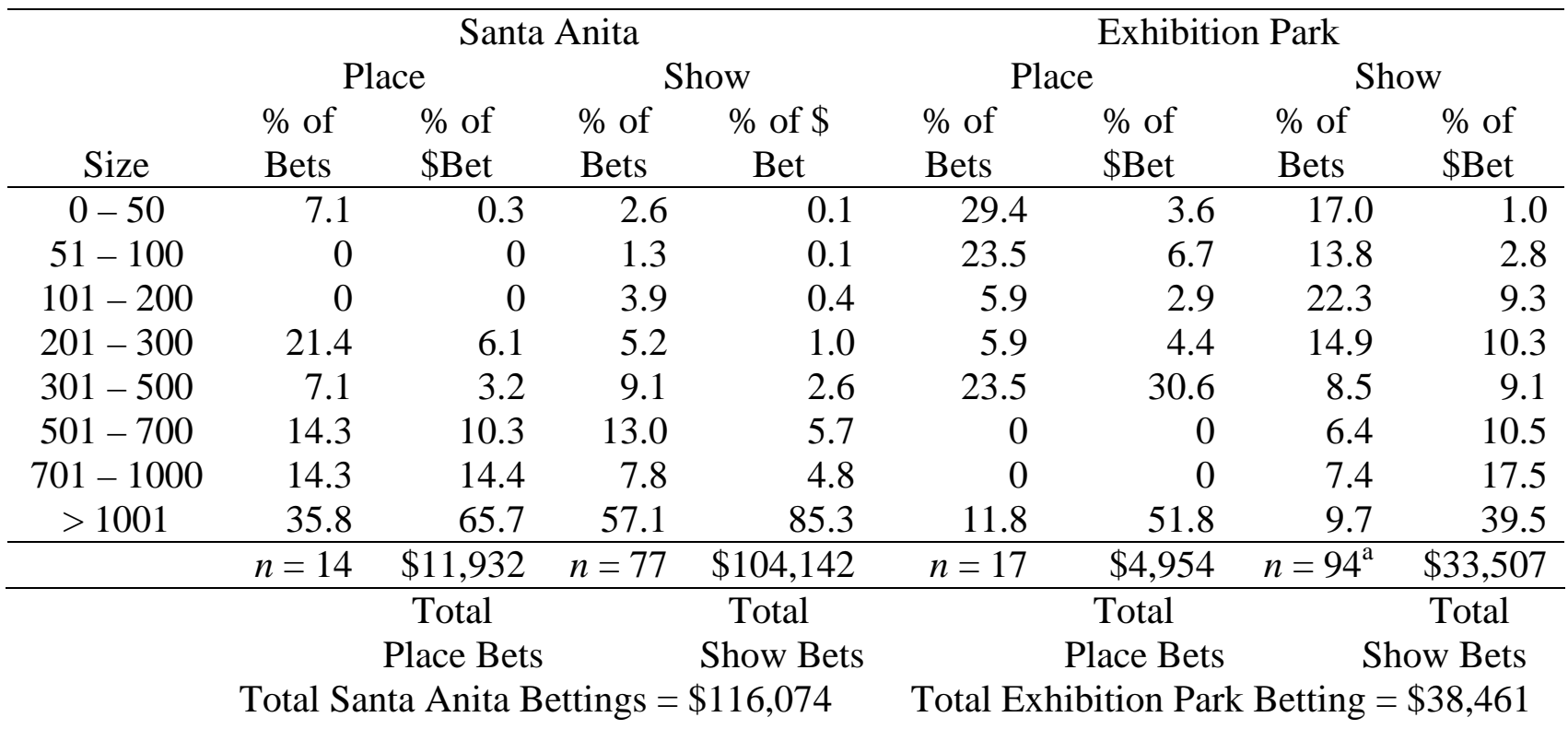

${ }^{\text {a }}$ Two of these bets had $E X_{s}^{l} \geq 1.20$ and $s_{l}^{*}=0$.

\section{Making the System Operational}

The calculations reported in Figures 1 and 2 were made under the assumption that the investor is free to bet once all other bettors have placed their bets. In practice one can only attempt to be one of the last bettors. ${ }^{12}$ There is a natural tradeoff between placing a bet too early and increasing the inaccuracies and running the possibility of arriving too late at the betting window to place a bet. ${ }^{13}$ The time just prior to the beginning of a race is crucial since many bets are typically made then including the so called "smart money" bets made very close to the beginning of the race so their impact on other bettors is minimized. It is thus extremely important that the investor be able to perform all calculations necessary to place the bet(s) very quickly. Typically, since tracks have neither public phones nor electricity, calculation can at most utilize battery operated calculators or possibly a battery operated special purpose computer. Even if computing

\footnotetext{
12 The model as developed in this paper utilizes an inefficiency in the place and show pools to yield positive profits. An investor's bets are determined by his wealth level as well as the profitability of one or more such bets. There may or may not exist "enough" inefficiency to provide positive profits for additional investors using a system of this nature. In the context of the Isaac's model, for win bets with linear utility, Thrall (1955) showed that if there were positive profits to be made and each new investor was aware of all previous investor's bets, then the profits for these various bettors are shared and in the limit become zero. It is likely that a similar result obtains for the model discussed here.

${ }^{13}$ At some tracks, such as Santa Anita, betting ends precisely at post time when the electric totalizator machines are shut off. At other tracks including Exhibition Park, betting ends when the horses enter the starting gate, that may be 2 or even 3 minutes past the post time.
} 
times were negligible, the very act of punching in the data needed for an exact calculation is too time-consuming since it takes more than one minute. Therefore, in practice, approximations that utilize a limited number of input data elements are required. Several types of approximations are possible such as the tabular rules of thumb developed by King (1978) or the regression procedures suggested here. Our procedure indicates whether or not a bet to place or show is warranted and at what level using the following eight data inputs: $w_{0}, W_{i^{*}}, P_{i^{*}}, Q_{j^{*}}, S_{j^{*}}, W, P$ and $S$, where $i^{*}$ is an $i$ for which $\left(W_{i} / W\right) /\left(P_{i} / P\right)$ is maximized and $j^{*}$ is a $j$ for which $\left(W_{j} / W\right) /\left(S_{j} / S\right)$ is maximized. It is easy to determine $i^{*}$ and $j^{*}$, particularly since $i^{*}$ often equals $j^{*}$, by inspection of the tote board. The approximation supposes that the only possible bets are $i^{*}$ to place and $j^{*}$ to show. The regressions, as given below, must be calibrated to a given track and initial wealth level. As a prelude to actual betting the regressions were calibrated at Exhibition Park for $w_{0}=$ $\$ 2500$. For calculated $i^{*}$, the expected return on a $\$ 1$ bet to place is approximated by

$$
E \tilde{X}_{l^{*}}^{p}=0.39445+0.51338 \frac{W_{i^{*}} / W}{\mathrm{P}_{i^{*}} / \mathrm{P}}, \quad R^{2}=0.776 .
$$

If $E \tilde{X}_{i^{*}}^{p} \geq 1.20$, then the optimal bet to place is approximated by

$$
\begin{aligned}
p_{i^{*}}=- & 459.32+1715.6 q_{i^{*}}-0.042518 q_{i^{*}} \mathrm{P}-7440.1 q_{i^{*}}^{2} \\
& +13791 q_{i^{*}}^{3}+0.10247 \mathrm{P}_{i^{*}}+49.572 \ln w_{0}, \quad R^{2}=0.954 .
\end{aligned}
$$

Similarly for $j^{*}$, the expected return on a $\$ 1$ bet to show is approximated by

$$
E \tilde{X}_{j^{*}}^{s}=0.64514+0.32806 \frac{W_{j^{*}} / W}{S_{j^{*}} / S}, \quad R^{2}=0.650
$$

If $E \tilde{X}_{j}^{s} \geq 1.20$, then the optimal bet to show is approximated by

$$
\begin{aligned}
s_{j^{*}}=- & 660.97-867.69 q_{j^{*}}+0.25933 q_{j^{*}} S+3715.2 q_{j^{*}}^{2} \\
& -0.19572 S_{j^{*}}+77.014 \ln w_{0}, \quad R^{2}=0.970 .
\end{aligned}
$$

All the coefficients in (7)-(10) are highly significant at levels not exceeding 0.05. Utilizing the equations (7)-(10), results in a scheme in which the data input and execution time on a modern hand held programmable calculator is about 35 seconds.

The results of utilizing this method on the Exhibition Park data with initial wealth of $\$ 2,500$ are shown in Figure 3, functions 1 and 2. Using the exact calculations, yields a final wealth of $\$ 5,197$ while the approximation scheme has an even higher final wealth of $\$ 7,698$. The approximation scheme leads to 63 more bets (174 versus 111) than the exact calculation. Since these bets had a positive net return, the total profit of the approximation scheme exceeds that of the exact calculation. Thus, it is clear that one would maximize profits with a cutoff rule below the conservative level of 1.20. The size distribution of bets from the exact and approximate solutions are remarkably similar; see Table 6 in Hausch, Ziemba and Rubinstein (1980). 
10,000

9,000

8,000

7,000

6,000

$W_{0}=\quad 5,000$

4,000

3,000

2,000

1,000

0

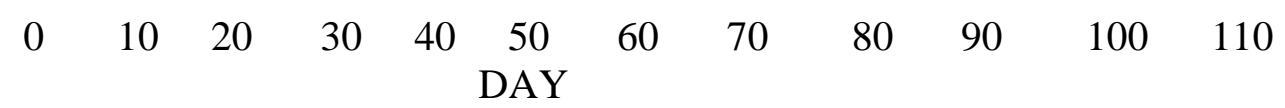

1 Results from expected log betting to place and show when expected returns are 1.20 or better with initial wealth $\$ 2,500$.

${ }_{2}^{2}$ Results from using the approximate regression scheme with initial wealth $\$ 2,500$.

FIGURE 3. Wealth Level Histories for Exact and Approximate Regression Betting Schemes; Exhibition Park: 1978 Season.

For place, there were 17 bets where $E X^{p}$ exceeded or equaled 1.20 of which $7(41 \%)$ were in the money. Only 2 of these 17 bets were not chosen by the regression. However 14 horses were chosen for betting by the regressions even though their "true" $E X^{p}$ was less than 1.20. Most of these had "true" $E X^{p}$ values close to 1.20 and were favorites. Four of these horses (29\%) were in-the-money. For show, there were 94 bets where $E X^{s}$ exceeded or equaled 1.20 of which 52 $(55 \%)$ were in-the-money. Only 8 of these were overlooked by the regressions, while 59 bets with "true" $E X^{s}$ values less than 1.20 were chosen by the regressions. Of these, 39 (66\%) were in-the-money.

The regression method is a simple procedure that seems to work well. For example using it on the Santa Anita data (without reestimating the coefficients) indicates that initial wealth of $\$ 2,500$ would yield a final wealth of $\$ 8,104$; see function 3 in Figure 1 . Conceivably, there are many possible refinements using fundamental information that could be added. Many of these 
refinements as well as discussion of the results of actual betting will appear in a forthcoming book by Ziemba and Hausch. One such refinement is the supposition that the win market is more efficient under normal fast track conditions and less efficient when the track is slow, muddy, heavy, wet, sloppy, etc. Bets were made on 87 of the 110 days at Exhibition Park; of these, 57 days had a fast track. Using the regression yields "fast track" bets of $\$ 32,501$ returning $\$ 38,364$ for a net profit of $\$ 5,863$. On the nonfast days the regressions suggest bets of $\$ 17,180$ returning $\$ 16,515$ for a loss of $\$ 665$. Hence this refinement decreases the time spent at the track and increases the net profit from $\$ 5,198$ to $\$ 5,863$.

\section{Implementation and Reliability of the System}

The model presented in this paper assumed that one can utilize the betting data that prevails at the end of the betting period, say $t$, to calculate optimal bets. In practice, however, even with the approximations given by (7)-(10), one requires about 1-1.5 minutes to physically calculate the optimal bets and place them. Thus one can only utilize betting information from $\tau(\approx t-1.5)$. Hence bets that were optimal at $\tau$ may not be as profitable at $t$. Some evidence by Ritter (1978) seems to indicate that the odds on the expost favorite at $t$ often decrease from $\tau$ to $t$. In which case, an optimal bet at $\tau$ may be a poor bet at $t$. Ritter investigated the systems: bet on $i *$ if $\left(P_{i^{*}} / P /\left(W_{i^{*}} / W\right) \leq 0.7\right.$ and on $j^{*}$ if $\left(S_{j^{*}} / S\right) /\left(W_{j^{*}} / W\right) \leq 0.7$. (For comparison equations (7) and (9) indicate the more restrictive constraints 0.6373 and 0.5912 , respectively, instead of 0.7 . The less restrictive Ritter constraints yield about three times as many bets as (7) and (9) indicate.) Using a sample of 229 harness races at Sportsman's Park and Hawthorne Park in Chicago he found that with $\$ 2$ bets these systems gained $24 \%$ and $16 \%$, respectively. But a $15 \%$ advantage shrunk to $1 \%$ if one uses the $\tau$ bets with a random shock over the $\tau$ to $t$ period (for the show bets for the 95 races at Hawthorne with a 0.65 cutoff). There are some difficulties with the design of Ritter's experiment, such as the small sample, the inclusion of only $\$ 2$ bets and the use of a random shock rather than an estimate of usual trends from $\tau$ to $t$, etc.; however, his results point to the difficulty of actually making substantial profits in a racetrack setting.

An attempt was made during the summer 1980 racing season at Exhibition Park to implement the proposed system and observe the "end of betting problem." Nine racing days were attended during which 90 races were run. At $t-2$ minutes the win, place, and show data were recorded on any horse that, through equations (7) and (9), warranted a bet. Equations (8) and (10) were then used on this data to determine the regression estimates of the optimal bets. Updated toteboard data on these horses were recorded until the end of betting to determine if the horse remained a system bet. Results of this experiment are shown in Table 5 where: 1) an initial wealth of $\$ 2,500$ is assumed; 2) size of bet calculations are done on data at $t-2$ minutes; and 3 ) returns are based on final data. Twenty-two bets were made that yielded final wealth of $\$ 3,716$ for a profit of $\$ 1,216$. Actual betting was not done, but making the calculations two minutes before the end of betting, allows 1.5 minutes to place the bet, more than enough time. Note in Table 5 that many systems bets at $t-2$ were not system bets at $t$; however, all had regression expected returns of more than one. 
TABLE 5

Results from Summer 1980 Exhibition Park Betting

\begin{tabular}{|c|c|c|c|c|c|c|c|}
\hline Date & Race & $\begin{array}{c}\text { Regression } \\
\text { estimate of } \\
\text { expected } \\
\text { return per } \\
\text { dollar, } 2 \\
\text { minutes } \\
\text { before end } \\
\text { of betting }\end{array}$ & $\begin{array}{l}\text { Regression } \\
\text { estimate of } \\
\text { expected } \\
\text { return per } \\
\text { dollar, at } \\
\text { the end of } \\
\text { betting }\end{array}$ & $\begin{array}{c}\text { Regression } \\
\text { estimate of optimal } \\
\text { bet } 2 \text { minutes } \\
\text { before end of } \\
\text { betting }\end{array}$ & Finish & $\begin{array}{l}\text { Net return } \\
\text { based on } \\
\text { final data } \\
\text { with } \\
\text { consideration } \\
\text { of our bets } \\
\text { affecting } \\
\text { odds }\end{array}$ & $\begin{array}{c}\text { Final } \\
\text { wealth }\end{array}$ \\
\hline & & & & & & & $\$ 2,500$ \\
\hline July 2 & 9 & 120 & 122 & $\$ 19$, SHOW ON 4 & $5-6-7$ & $-\$ 19$ & 2,481 \\
\hline July 2 & 10 & 120 & 123 & 72, SHOW ON 8 & $8-1-2$ & 72 & 2,553 \\
\hline July 9 & 7 & 121 & 110 & 292, SHOW ON 1 & $2-7-1$ & 131 & 2,684 \\
\hline July 9 & 10 & 135 & 122 & 248, PLACE ON 1 & $1-6-2$ & 260 & 2,944 \\
\hline July 16 & 6 & 131 & 122 & 487, PLACE ON 9 & $9-8-6$ & 536 & 3,480 \\
\hline July 16 & 6 & 139 & 117 & 292, SHOW ON 9 & $9-8-6$ & 146 & 3,626 \\
\hline July 16 & 7 & 125 & 127 & 7, SHOW ON 1 & $5-2-8$ & -7 & 3,619 \\
\hline July 23 & 3 & 149 & 149 & 30, SHOW ON 2 & $2-10-7$ & 92 & 3,711 \\
\hline July 23 & 4 & 139 & 134 & 573, SHOW ON 10 & $6-10-4$ & 201 & 3,912 \\
\hline July 30 & 8 & 121 & 111 & 215, PLACE ON 4 & $4-1-5$ & 129 & 4,041 \\
\hline July 30 & 9 & 123 & 125 & 591, SHOW ON 6 & $8-1-5$ & -591 & 3,450 \\
\hline Aug 6 & 6 & 128 & 112 & 39, SHOW ON 4 & $4-3-1$ & 59 & 3,509 \\
\hline Aug 6 & 9 & 124 & 103 & 51 , SHOW ON 2 & $4-1-3$ & -51 & 3,458 \\
\hline Aug 8 & 1 & 121 & 132 & 87, SHOW ON 1 & $1-10-4$ & 139 & 3,597 \\
\hline Aug 8 & 3 & 127 & 111 & 635, SHOW ON 3 & $3-4-7$ & 127 & 3,724 \\
\hline Aug 8 & 4 & 126 & 113 & 126, SHOW ON 2 & $2-7-1$ & 82 & 3,806 \\
\hline Aug 11 & 8 & 121 & 112 & 94 , SHOW ON 8 & $8-6-2$ & 113 & 3,919 \\
\hline Aug 11 & 9 & 131 & 130 & 688 , SHOW ON 5 & $5-3-4$ & 138 & 4,057 \\
\hline Aug 13 & 3 & 128 & 106 & 33 , SHOW ON 2 & $1-6-7$ & -33 & 4,024 \\
\hline Aug 13 & 6 & 131 & 122 & 205, SHOW ON 5 & $5-8-4$ & 144 & 4,168 \\
\hline Aug 13 & 7 & 134 & 133 & 511, SHOW ON 6 & $8-5-9$ & -511 & 3,657 \\
\hline Aug 13 & 10 & 123 & 109 & 108, SHOW ON 5 & $3-5-1$ & 59 & 3,716 \\
\hline
\end{tabular}

An important question concerns the reliability of the results: are the results true exploitations of market inefficiencies or could they be obtained simply by chance? This question is investigated utilizing a simple model that was suggested to us by an anonymous referee. The first application is concerned with an estimate of the probability that the system's theory is vacuous and indeed that the observations conform to specific favorable samples from a random betting population. The second application estimates the probability of not making a positive profit. The calculations utilize the 1980 Exhibition Park data; see Table 5.

Let $\pi$ be the probability of winning a bet in each trial and 


$$
\begin{aligned}
& X_{i}=\{1+w \text { if the bet is won, } \\
& \{0 \text { otherwise, }
\end{aligned}
$$

be the return from a $\$ 1$ bet in trial $i$. In $n$ trials, the probability of winning at least $100 y \%$ of the total bet is

$$
\operatorname{Pr}\left[\frac{1}{n}\left(\sum_{i=1}^{n} X_{i}\right)-1>y\right]
$$

Assume that the trials are independent. Since the $X_{i}$ are binomially distributed, (11) can be approximated by a normal probability distribution as

$$
1-\Phi\left[\frac{\sqrt{n}\{y-(1+w) \pi+1\}}{(1+w) \pi \sqrt{(1-\pi) / \pi}}\right]
$$

where $\Phi$ is the cumulative distribution function of a standard $N(0,1)$ variable. The observed probability of winning a bet, weighted by size of bet made, yields 0.771 as an estimate of $\pi$. If the systems theory were vacuous and random betting were actually being made then $(1+w) \pi=$ 0.83 since the track's payback is approximately $83 \%$. The 22 bets made totaled $\$ 5,304$ and resulted in a profit of $\$ 1,216$ for a rate of return of $22.9 \%$. Using equation (12) with $n=22$, gives $3 \times 10^{-5}$ as the probability of making $22.9 \%$ through random betting.

Suppose that the 1980 Exhibition Park results represent typical system behavior so $\pi=0.771$ and $(1+w) \pi=1.229$. In $n$ trials the probability of making a non-positive net return is

$$
\operatorname{Pr}\left[\frac{1}{n}\left(\sum_{i=1}^{n} X_{i}\right)-1<0\right]
$$

which can be approximated as

$$
\Phi\left[\frac{\sqrt{n}(1-(1+w) \pi)}{(1-w) \pi \sqrt{(1-\pi) / \pi}}\right]=\Phi(-0.342 \sqrt{n}) .
$$

For $n=22$ this probability is only 0.054 and for $n=50$ and 100 this probability is 0.008 and 0.0003, respectively. Thus it is reasonable to suppose that the results from the 1980 Exhibition Park data (as well as the 1978 Exhibition Park and 1973/1974 Santa Anita data with their larger samples) represent true exploitation of a market inefficiency. 


\section{References}

Ali, M.M., "Probability and Utility Estimates for Racetrack Bettors," Journal of Political Economy 85 (1977), pp. 803-815.

Ali, M.M., "Some Evidence of the Efficiency of a Speculative Market," Econometrica 47, No. 2 (1979), pp. 387-392.

Arrow, K.J., Aspects of the Theory of Risk Bearing, Helsinki: Yrjö Jahnsson Foundation (1965).

Baumol, W.J., The Stock Market and Economic Efficiency, New York: Fordham University Press (1965).

Beyer, A., My \$50,000 Year at the Races, New York: Harcourt, Brace, Jovanovitch (1978).

Copeland, J.E. and J.F. Weston, Financial Theory and Corporate Policy, Reading, MA: Addison-Wesley (1979).

Downes, D. and T.R. Dyckman, "A Critical Look at the Efficient Market Empirical Research Literature as it Relates to Accounting Information," Accounting Review (April 1973), pp. 300317.

Fabricant, B.F., Horse Sense, New York: David McKay (1965).

Fama, E.F., "Efficient Capital Markets: A Review of Theory and Empirical Work," Journal of Finance 25 (1970), pp. 383-417.

Fama, E.F., Foundations of Finance, New York: Basic Books (1976).

Figlewski, S., "Subjective Information and Market Efficiency in a Betting Model," Journal of Political Economy 87 (1979), pp. 75-88.

Griffith, R.M., "Odds Adjustments by American Horse Race Bettors," American Journal of Psychology 62 (1949) pp. 290-294.

Griffith, R.M., "A Footnote on Horse Race Betting," Transactions of the Kentucky Academy of Sciences 22 (1961), pp. 78-81.

Harville, D.A., "Assigning Probabilities to the Outcomes of Multi-Entry Competitions," Journal of the American Statistical Association 68 (1973), pp. 312-316.

Hausch, D.B., W.T. Ziemba and M. Rubinstein, "Efficiency of the Market for Racetrack Betting," U.B.C. Faculty of Commerce, working paper No. 712 (September 1980).

Isaacs, R., “Optimal Horse Race Bets,” American Mathematical Monthly (1953), pp. 310-315. 
King, A.P., "Market Efficiency of a Multi-Entry Competition," MBA essay, Graduate School of Business, University of California, Berkeley (June 1978).

McGlothlin, W.H., "Stability of Choices Among Uncertain Alternatives," American Journal of Psychology 63 (1956), pp. 604-615.

Pratt, J., "Risk Aversion in the Small and in the Large," Econometrica (1964), pp. 122-136.

Ritter, J.R., "Racetrack Betting: An Example of a Market with Efficient Arbitrage," notes, Department of Economics, University of Chicago (March 1978).

Rosett, R.H., “Gambling and Rationality,” Journal of Political Economy 73 (1965), pp. 595-607.

Rubinstein, M., "Securities Market Efficiency in an Arrow-Depreu Market," American Economic Review 65, No. 5 (1975), pp. 812-824.

Seligman, D., “A Thinking Man’s Guide to Losing at the Track," "Fortune 92 (1975), pp. 81-87.

Snyder, W.W., "Horse Racing: Testing the Efficient Markets Model," Journal of Finance 33 (1978) pp. 1109-1118.

Thrall, R.M., "Some Results in Non-Linear Programming," Proceedings of the Second Symposium in Linear Programming 2, National Bureau of Standards, Washington, D.C., January 27-29, 1955, pp. 471-493.

Vergin, R.C., "An Investigation of Decision Rules for Thoroughbred Race Horse Wagering," Interfaces 8, No. 1 (1977), pp. 34-45.

Weitzman, M., "Utility Analysis and Group Behaviour: An Empirical Study," Journal of Political Economy 73 (1965), pp. 18-26.

Ziemba, W.T. and R.G. Vickson, editors, Stochastic Optimization Models in Finance, New York: Academic Press (1975). 